\title{
Socio-demographic Determinants of Water Treatment in Cholera Patients and Clinical Presentation of Disease: A Decade of Observation from a Large Urban Diarrhoeal Disease Hospital in Bangladesh
}

\author{
Ali $\mathrm{MF}^{1}$, Malek $\mathrm{MA}^{2}$, Faruque $\mathrm{ASG}^{2}$ \\ ${ }^{I}$ Department of Medicine, Winthrop-University Hospital, Mineola, USA, \\ ${ }^{2}$ Center for Nutrition and Food Security (CNFS,) ICDDR, B, Dhaka, Bangladesh. \\ e-mail: mohammadfahad.ali@gmail.com
}

\begin{abstract}
Cholera remains a health problem around the globe including Bangladesh, and claims thousands of lives and places a substantial strain on public health resources. Data collected from 4,894 cholera patients who presented to Dhaka Hospital of icddr,b between 2004 and 2013, and were analysed to assess the socio-demographic determinants of water treatment and their impact on cholera, and examine the possible influence of water treatment on changing clinico-pathologic predictors in cholera patients. Results of this study consistently showed strong association between water treatment and male sex, family income, slum residence and hygiene. Stool characteristics, vomiting, concomitant infection with ETEC, dehydration and rehydration with IV fluids were clinically significant factors. Although socio-demographic factors remain strong determinants of water treatment among cholera patients, increasing severity of the clinical manifestations of cholera as indicated by this study suggest greater burden of inoculation or more possibly increased virulence of these organisms.
\end{abstract}

\section{Introduction}

Cholera remains a global healthcare dilemma. According to Global Health Observatory (GHO) data of the World Health Organization (WHO) 190,549 cholera cases were reported by 42 countries from all continents in 2014 (55\% were reported from Africa and $15 \%$ from the Americas). An estimated 1.4 to 4.0 million people contract cholera each year in endemic countries around the world, and some 21,000 to 143,000 people die from infection by the bacteria Vibrio cholerae (O1 and O139). ${ }^{1}$

In Bangladesh, there are approximately two peaks each year: roughly one before and one after the monsoon. ${ }^{2}$ The epidemics of 2002, with an estimated 30,000 cases of cholera ${ }^{3}$, and the large spate of cases, around 14,000 in number, after the severe flooding of 2007 is fresh in our memories. Harris et al in their paper highlighted the shifting prevalence of major pathogens observed during the flooding episodes of 1998 , 2004, and $2007 .^{7}$

The importance of implementing water chlorination and filtration at public water sources and point-of-use water purification technologies and sanitation (sewage systems and latrines) interventions is paramount. Although, ensuring these basic amenities will probably help us to make the largest dent in our efforts to effectively control and prevent cholera, we must realize their time- and labor- consuming nature. Thus, alternative short-term approaches that bring about immediate response such as oral cholera vaccines are gaining traction. The WHO in their position paper on cholera vaccines states that the available oral vaccines are safe and deliver sustained protection of $>50 \%$ that lasts for two years in endemic populations. ${ }^{14}$ 
Better understanding of the pathophysiology and pattern of disease, improved access to cleaner drinking water and sewage facilities, and the advent of oral vaccines have been useful tools in our armory to fight cholera, but we still have a way to go before we can eradicate it altogether. In order to achieve that goal, we also have to monitor and appreciate the evolving character of cholera. The objectives of this paper given the current scenario were to: i) assess the sociodemographic determinants of water treatment and their impact on cholera, by utilizing the surveillance system of Dhaka Hospital which prospectively collects water treatment and other relevant histories, and ii) examine the influence of water treatment on changing clinicopathologic predictors in cholera patients. The time period investigated spans from 2004 to 2013, divided into two observation points, 2004 to 2008 and 2009 to 2013.

\section{Materialsand Methods}

Study population and site:The study was conducted at Dhaka Hospital of The International Centre for Diarrhoeal Disease Research, Bangladesh (icddr,b). Founded in 1968, the hospital provides care to around 140,000 patients annually for their diarrhoea and/or other health problems. Starting in 1979, it established the Diarrhoeal Disease Surveillance System (DDSS) to collect information on demographic, epidemiological and clinical characteristics of patients. A systematic $2 \%$ sub-sample (every fiftieth patient, irrespective of age, sex, and severity of diarrhoea) of patients attending the Dhaka Hospital from the DDSS area was enrolled. DDSS monitors changes in the characteristics of the patients and etiology of their diarrhea, detects emergence of new diarrheagenic pathogens and/or re-emergence of conventional pathogens, and studies changes in the antimicrobial susceptibility of enteric bacterial pathogens.
Source of data and hospital surveillance system : Every fiftieth patient (2\% systematic sample of all patients) has his or her information collected by a trained research assistant. Data ranging from illness characteristics and socio-economic background to hygiene practices and environmental characteristics were recorded using a pre-tested structured data-collection tool. A clinician obtains medical history, performs thorough physical examination, and records findings on prescribed forms. Information was entered and maintained in the electronic database of the DDSS. ${ }^{4}$

Laboratory methods: Fresh stool (or rectal swab) specimens were collected from all enrolled patients for laboratory assays to identify bacterial, viral and parasitic enteric pathogens following standard laboratory methods. ${ }^{5}$ In the laboratories, faecal specimens (rectal swabs from a few who were unable to produce stool) were directly plated onto selective media for isolation and identification of common bacterial enteric pathogens (e.g. Shigella, Salmonella, ETEC) and serogrouping and serotyping using specific antisera by standard methods. Rotavirus was detected by stool ELISA, and stool microscopy was done for detection of parasites (Giardia lamblia, Entamoeba histolytica, and Cryptosporidium) and ova and trophozoites of helminthes.

Data analysis: Data relating to 4,894 cholera patients from 2004 to 2013 were analyzed using SPSS for Windows (version 12.0; SPSS Inc., Chicago) and Epi info (version 6.0, USD, Stone Mountain, GA). The time interval (2004-2013), was divided into two 5-year blocks from 2004 to 2008 and from 2009 to 2013, to enable appropriate comparison and better assessment of trends across time points. Univariate chi-square analysis was performed for each 5-year period, where individual socioeconomic/demographic (e.g. age, sex, family income, area of residence, hygiene) and clinico-pathologic indicators ( e.g. 
stool characteristic, number of stools, duration of diarrhea, abdominal pain, vomiting, fever, severity of dehydration, concomitant infection with other pathogens) was cross tabulated with water treatment method (boiled drinking water Vs. unboiled drinking water). Strength of association was determined by estimating odds ratios (OR) and their 95\% confidence intervals (CI); a $p$-value of less than 0.05 was considered significant.

Two logistic regression models- one utilizing sociodemographic factors and the other, clinicopathologic factors were created for each 5 year period and then compared for further clues indicative of change.

Ethical statement: DDSS of icddr,b is a routine ongoing activity of Dhaka Hospital which has been approved by the Research Review Committee (RRC) and Ethical Review Committee (ERC). At the time of enrollment, verbal and written consent was obtained from patients or caregivers/guardians on behalf of patients $(<5$ years of age). The information was then stored in the hospital database and consequently used for conducting research.

\section{Results}

A total of 4,894 cholera patients (43\% females and $57 \%$ males) were enrolled in the study. Overall, about $72 \%$ of the total cholera patients did not boil their water between 2004 and 2008, compared to about $65 \%$ of cholera patients who did not boil their water during 2009 to 2013.

Univariate analysis of data from the first 5-year period (2004 to 2008) displayed strong association, as reflected through odds ratios $\left(\mathrm{OR}^{1}\right)$ and $p$ values, between water treatment and the following socio-demographic factors: sex (male), monthly family income (<100 USD), area of residence (slums), and hygiene (nonsanitary toilet). No such association was to be found with the various age groups $(<5$ years, 5-19 years, and $>19$ years). Odds were high that cholera patients with monthly family incomes $<100$ USD, residing in slums, and practicing poor hygiene did not boil their drinking water. Some $82 \%$ of cholera patients who did not treat their water earned $<100$ USD; $51.4 \%$ of cholera patients who did not boil their water used nonsanitary toilets. Amongst clinical indicators, strong association was noticed between water treatment and stool characteristics (watery), vomiting, some/severe dehydration, and concomitant infection with ETEC. Ninety five percent of cholera patients who did not boil their water complained of vomiting and exhibited some or severe dehydration. Odds were significantly high that cholera patients who did not boil their water would likely present with dehydration and concomitant infection with ETEC. No association was established with number of stools ( $>10$ episodes), abdominal pain, fever, duration of diarrhea ( $>1$ day), resuscitation (IV fluids), and concomitant infection with rotavirus or shigella.

Univariate analysis of data from the second 5year period (2009 to 2013) displayed strong association, as reflected through odds ratios $\left(\mathrm{OR}^{2}\right)$ and $p$ values, between water treatment and the following socio-demographic factors: sex (male), monthly family income (<100 USD), area of residence (slums), hygiene (non-sanitary toilet), and additionally age $<5$ years. Age between 5 and 19 years had a protective effect. $60 \%$ of male cholera patients did not boil their drinking water. Amongst clinical indicators, strong association was noticed between water treatment and vomiting, some/severe dehydration, concomitant infection with ETEC, as well as rehydration using intravenous fluids. Odds were significantly high that cholera patients who did not boil their water would present with dehydration and likely require intravenous fluids for volume repletion. No association was established with stool characteristics (watery), number of stools (>10 episodes), abdominal pain, 
fever, duration of diarrhea ( $>1$ day), and concomitant infection with rotavirus or shigella.

For actual odds ratios, $p$ values, and 95\% CI ( table I)

Table I: Univariate analysis of patient socio-demographic and clinical, and pathologic characteristics from years 2004 to 2008 , and 2009 to 2013 .

\begin{tabular}{llcccc}
\hline & \multicolumn{3}{c}{$2004-2008$} & & $2009-2013$ \\
Indicators & Boiled & Boiled & $\mathrm{OR}^{1}$ & Un- & $\mathrm{OR}^{2}$ \\
& water & water & $(95 \% \mathrm{CI})$ & boiled & $(95 \% \mathrm{CI}) p$ \\
& $\mathrm{n}(\%)$ & $\mathrm{n}(\%)$ & $p$ value & water & value \\
& & & $\mathrm{n}(\%)$ & \\
\hline
\end{tabular}

\begin{tabular}{|c|c|c|c|c|c|c|}
\hline \multicolumn{7}{|c|}{ Socio-demographic Characteristics } \\
\hline Male & $381(55)$ & $\begin{array}{l}434 \\
(52)\end{array}$ & $\begin{array}{c}1.21 \\
(1.02- \\
1.41) \\
0.029\end{array}$ & $\begin{array}{c}767 \\
(60)\end{array}$ & & $\begin{array}{l}1.21 \\
(1.0- \\
1.47) \\
0.05\end{array}$ \\
\hline $\begin{array}{c}\text { Age } \\
<5 \\
\text { years }\end{array}$ & $156(23)$ & $\begin{array}{l}171 \\
(21)\end{array}$ & $\begin{array}{c}1.01 \\
(0.82- \\
1.23) \\
0.983\end{array}$ & $\begin{array}{l}216 \\
(17)\end{array}$ & & $\begin{array}{c}1.44 \\
(1.14- \\
1.81) \\
<0.001\end{array}$ \\
\hline $\begin{array}{c}\text { Age 5- } \\
19 \\
\text { years }\end{array}$ & $145(21)$ & $\begin{array}{l}220 \\
(27)\end{array}$ & $\begin{array}{c}0.87 \\
(0.72- \\
1.05) \\
0.139\end{array}$ & $\begin{array}{l}336 \\
(26)\end{array}$ & & $\begin{array}{c}0.75 \\
(0.59- \\
0.93) \\
0.010\end{array}$ \\
\hline $\begin{array}{l}\text { Age } \\
>19 \\
\text { years }\end{array}$ & $\begin{array}{c}1051 \\
(50)\end{array}$ & $\begin{array}{l}437 \\
(53)\end{array}$ & $\begin{array}{c}1.11 \\
(0.95- \\
1.31) \\
0.201\end{array}$ & $\begin{array}{l}725 \\
(57)\end{array}$ & $\begin{array}{l}387 \\
(56)\end{array}$ & $\begin{array}{c}0.98 \\
(0.81- \\
1.19) \\
0.861\end{array}$ \\
\hline $\begin{array}{c}\text { Monthl } \\
y \\
\text { family } \\
\text { income } \\
(<100 \\
\text { USD) }\end{array}$ & $\begin{array}{c}1714 \\
(82)\end{array}$ & $\begin{array}{l}472 \\
(57)\end{array}$ & $\begin{array}{c}3.38 \\
(2.82- \\
4.04) \\
<0.001\end{array}$ & $\begin{array}{l}494 \\
\text { (39) }\end{array}$ & $\begin{array}{l}149 \\
(22)\end{array}$ & $\begin{array}{c}2.28 \\
(1.83- \\
2.84) \\
<0.001\end{array}$ \\
\hline $\begin{array}{c}\text { Area } \\
\text { of } \\
\text { residen } \\
\text { ce } \\
\text { (slums } \\
\text { ) }\end{array}$ & $275(13)$ & $\begin{array}{l}35 \\
(4)\end{array}$ & $\begin{array}{c}3.42 \\
(2.35- \\
4.99) \\
<0.001\end{array}$ & $\begin{array}{c}164 \\
\text { (13) }\end{array}$ & $\begin{array}{l}27 \\
(4)\end{array}$ & $\begin{array}{c}3.60 \\
(2.33- \\
5.60) \\
<0.001\end{array}$ \\
\hline $\begin{array}{c}\text { Hygien } \\
\text { e } \\
\text { (non- } \\
\text { sanitar } \\
\text { y } \\
\text { toilet) }\end{array}$ & $\begin{array}{c}1079 \\
(51)\end{array}$ & $\begin{array}{l}161 \\
(19)\end{array}$ & $\begin{array}{c}4.38 \\
(3.60- \\
5.34) \\
<0.001\end{array}$ & $\begin{array}{l}347 \\
(27)\end{array}$ & $\begin{array}{l}43 \\
(6)\end{array}$ & $\begin{array}{c}5.60 \\
(3.92- \\
7.92) \\
<0.001\end{array}$ \\
\hline
\end{tabular}

\begin{tabular}{ccccccc}
\hline \multicolumn{7}{c}{ Clinical Characteristics } \\
\hline Stool & 209 & & 3.13 & & \\
characteristi & 0 & 817 & $(1.20-$ & 1263 & 678 & $(0.55-$ \\
cs (watery) & $(99$ & $(99)$ & $8.21)$ & $(99)$ & $(99)$ & $3.20)$ \\
& ) & & 0.016 & & & 0.637 \\
Number of & 115 & & 0.99 & & & 1.01 \\
stools (>10 & 8 & 458 & $(0.84-$ & 802 & 430 & $(0.83-$ \\
episodes) & $(55$ & $(55)$ & $1.19)$ & $(63)$ & $(63)$ & $1.23)$ \\
& $\quad$ & & 0.976 & & & 0.933 \\
Abdominal & 899 & 372 & $(0.92$ & & & 1.21 \\
pain & $(43$ & $(45)$ & $1.08)$ & $(44)$ & $(39)$ & $1.47)$ \\
& ) & & 0.322 & & & 0.054 \\
& 199 & & 1.44 & & & 1.85 \\
Vomiting & 5 & 770 & $(1.02-$ & 1159 & 579 & $(1.39-$ \\
& $(95$ & $(93)$ & $2.04)$ & $(91)$ & $(84)$ & $2.47)$ \\
& ) & & 0.036 & & & $<0.001$ \\
Fever & 15 & 3 & 1.98 & & & 0.74 \\
& $(1)$ & $(0.4)$ & $8.62)$ & $(3)$ & $(4)$ & $1.25)$ \\
& & & 0.402 & & & 0.292
\end{tabular}

\begin{tabular}{|c|c|c|c|c|c|c|}
\hline $\begin{array}{l}\text { Duration of } \\
\text { diarrhea } \\
\text { (>1day) }\end{array}$ & $\begin{array}{l}729 \\
(35 \\
)\end{array}$ & $\begin{array}{l}300 \\
(36)\end{array}$ & $\begin{array}{l}0.94 \\
(0.79- \\
1.11) \\
0.469\end{array}$ & $\begin{array}{l}401 \\
(31)\end{array}$ & $\begin{array}{l}232 \\
(34)\end{array}$ & $\begin{array}{l}0.90 \\
(0.74- \\
1.10) \\
0.318\end{array}$ \\
\hline $\begin{array}{l}\text { Dehydratio } \\
\mathrm{n} \text { (some or } \\
\text { severe) }\end{array}$ & $\begin{array}{l}200 \\
0 \\
(95 \\
)\end{array}$ & $\begin{array}{l}772 \\
(93)\end{array}$ & $\begin{array}{l}1.48 \\
(1.04- \\
2.10) \\
0.028\end{array}$ & $\begin{array}{l}1208 \\
(95)\end{array}$ & $\begin{array}{l}602 \\
(88)\end{array}$ & $\begin{array}{l}2.51 \\
(1.77- \\
3.55) \\
<0.001\end{array}$ \\
\hline $\begin{array}{l}\text { Resuscitatio } \\
\mathrm{n} \\
\text { (intravenou } \\
\text { s saline) }\end{array}$ & $\begin{array}{l}168 \\
0 \\
(81 \\
)\end{array}$ & $\begin{array}{l}645 \\
(79)\end{array}$ & $\begin{array}{l}1.12 \\
(0.91- \\
1.39) \\
0.298\end{array}$ & $\begin{array}{l}1015 \\
(80)\end{array}$ & $\begin{array}{l}487 \\
(71)\end{array}$ & $\begin{array}{l}1.61 \\
(1.29- \\
2.01) \\
<0.001\end{array}$ \\
\hline Pathogens & & & & & & \\
\hline Rotavirus & $\begin{array}{l}62 \\
(3)\end{array}$ & $29(4)$ & $\begin{array}{l}0.84 \\
(0.52- \\
1.35) \\
0.514\end{array}$ & $\begin{array}{l}46 \\
\text { (4) }\end{array}$ & $\begin{array}{l}26 \\
(4)\end{array}$ & $\begin{array}{l}0.95 \\
(0.57- \\
1.60) \\
0.944\end{array}$ \\
\hline Shigella & $\begin{array}{l}26 \\
(1)\end{array}$ & $15(2)$ & $\begin{array}{l}0.68 \\
(0.34- \\
2.90) \\
0.312\end{array}$ & $\begin{array}{l}11 \\
\text { (1) }\end{array}$ & $\begin{array}{l}11 \\
(2)\end{array}$ & $\begin{array}{l}0.53(0.2 \\
1-1.33) \\
0.208\end{array}$ \\
\hline ETEC & $\begin{array}{l}56 \\
(3)\end{array}$ & $38(5)$ & $\begin{array}{l}1.75 \\
(1.15- \\
2.67) \\
0.008 \\
\end{array}$ & $\begin{array}{l}93 \\
\text { (7) }\end{array}$ & $\begin{array}{l}79 \\
(12)\end{array}$ & $\begin{array}{l}1.65 \\
(1.20- \\
2.26) \\
<0.001 \\
\end{array}$ \\
\hline
\end{tabular}

Multivariate analysis (logistic regression model) of socio-demographic factors in the first observation point (2004 to 2008) confirmed the significance of sex (male), monthly family income (<100 USD), area of residence (slums), and hygiene (non-sanitary toilet) with regards to water treatment in cholera patients. When looking at clinico-pathologic factors, stool characteristics and concomitant infection with ETEC showed significance.

Table II: Multivariate analysis/Logistic regression Models of patient socio-demographic characteristics from years 2004 to 2008, and 2009 to 2013.

\begin{tabular}{|c|c|c|c|c|}
\hline \multirow[b]{2}{*}{ Indicators } & \multicolumn{2}{|c|}{$2004-2008$} & \multicolumn{2}{|c|}{$2009-2013$} \\
\hline & $\begin{array}{c}\text { OR }(95 \% \\
\text { CI })\end{array}$ & $\begin{array}{c}P \\
\text { value }\end{array}$ & $\begin{array}{c}\text { OR ( } \\
95 \% \mathrm{CI})\end{array}$ & $p$ value \\
\hline \multicolumn{5}{|c|}{ Socio-Demographic Characteristics } \\
\hline $\begin{array}{l}\text { Age }(<5 \\
\text { years })\end{array}$ & $\begin{array}{c}0.872 \\
(0.677- \\
1.123)\end{array}$ & 0.288 & $\begin{array}{c}0.720 \\
(0.632- \\
0.820)\end{array}$ & $<0.001$ \\
\hline $\begin{array}{c}\text { Sex } \\
\text { (Male) }\end{array}$ & $\begin{array}{c}1.335 \\
(1.122- \\
1.590)\end{array}$ & 0.001 & $\begin{array}{c}1.214 \\
(1.126- \\
1.309)\end{array}$ & $<0.001$ \\
\hline $\begin{array}{l}\text { Area of } \\
\text { Residence } \\
\text { (slums) }\end{array}$ & $\begin{array}{c}2.022 \\
(1.384- \\
2.955)\end{array}$ & $<0.001$ & $\begin{array}{c}2.067 \\
(1.724- \\
2.478)\end{array}$ & $<0.001$ \\
\hline Monthly & & & & \\
\hline $\begin{array}{l}\text { Family } \\
\text { Income } \\
(<100 \\
\text { USD })\end{array}$ & $\begin{array}{c}2.620 \\
(2.176- \\
3.153)\end{array}$ & $<0.001$ & $\begin{array}{c}1.544 \\
(1.409- \\
1.693)\end{array}$ & $<0.001$ \\
\hline $\begin{array}{l}\text { Place of } \\
\text { Defecation } \\
\text { (non- } \\
\text { sanitary) }\end{array}$ & $\begin{array}{c}3.684 \\
(3.019- \\
4.496)\end{array}$ & $<0.001$ & $\begin{array}{c}5.952 \\
(5.166- \\
6.858)\end{array}$ & $<0.001$ \\
\hline
\end{tabular}


Similarly, multivariate analysis (logistic regression model) of socio-demographic factors in the second observation point (2009 to 2013) confirmed the significance of age $<5$ years, monthly family income ( $<100$ USD), area of residence (slums), and hygiene (non-sanitary toilet) with regards to water treatment in cholera patients. When looking at clinico-pathologic factors, dehydration (some or severe), resuscitation, vomiting, stool characteristics and concomitant infection with ETEC showed significance.

Table III: Multivariate analysis/Logistic regression Models of patient clinico-pathologic characteristics from years 2004 to 2008, and 2009 to 2013.

\begin{tabular}{ccccc}
\hline \multirow{5}{*}{ Indicators } & \multicolumn{2}{c}{$2004-2008$} & \multicolumn{2}{c}{$2009-2013$} \\
& OR & $p$ & OR ( & \\
& $(95 \%$ CI $)$ & value & $95 \%$ CI $)$ & $p$ value \\
\hline \multicolumn{5}{c}{ Clinico-pathologic Characteristics } \\
Stool & 2.509 & & 1.192 & \\
Characteristi & $(1.019-$ & 0.045 & $(1.029-$ & 0.019 \\
cs (watery) & $6.179)$ & & $1.380)$ & \\
& 1.356 & & 1.151 & \\
Vomiting & $(0.955-$ & 0.089 & $(1.060-$ & 0.001 \\
& $1.926)$ & & $1.251)$ & \\
& 1.408 & & 1.221 & \\
Dehydration & $(0.958-$ & 0.082 & $(1.120-$ & $<0.001$ \\
& $2.070)$ & & $1.330)$ & \\
& 0.957 & & 1.288 & \\
Rehydration & $(0.762-$ & 0.708 & $(1.174-$ & $<0.001$ \\
& $1.203)$ & & $1.414)$ & \\
ETEC & 0.553 & & 0.763 & \\
& $(0.362-$ & 0.006 & $(0.676-$ & $<0.001$ \\
& $0.845)$ & & $0.862)$ & \\
\hline
\end{tabular}

\section{Discussion}

The global burden of cholera is substantial, and WHO estimates that 1.4 million to four million cases and up to 140,000 deaths attributed to cholera annually. ${ }^{6}$ The floods of 1998, 2002, 2004, and 2007 brought along with them tens of thousands of cases of diarrheal diseases.

The government of Bangladesh has addressed the socio-demographic aspects of cholera through the development of water and sewage treatment systems to ensure safe drinking water and safe disposal of sewage for all. A lot of headway has been made with respect to both these objectives.
A study by the World Bank's water and sanitation programme showed that $76-90 \%$ of the population were obtaining drinking-water from an improved source and $50-75 \%$ of the population were using improved sanitation facilities in $2010 .^{8}$ Findings of this study, reflected these infrastructure-based changes. The proportion of illiterate cholera patients who drank untreated water shrank when comparing the two time points (2004-2008 Vs. 2009-2013; $45.5 \%$ Vs. $35.9 \%$ ). Even more dramatic shifts were noticed in family income and sanitation. In the time period of $2004-2008,18.3 \%$ of cholera patients who drank unboiled water reported monthly family income of greater than or equal to 100 USD and $51.4 \%$ mentioned non-sanitary defecation practices. Whereas, from 2009-2013, $61.3 \%$ of the cholera patients who drank unboiled water reported monthly family income of greater than or equal to 100 USD and $27.2 \%$ endorsed non-sanitary defecation conditions.

As far as the clinico-pathologic components are concerned, results of the current study indicated a trend towards greater severity of illness at presentation among cholera patients requiring concerted resuscitative efforts. Clinical indicators such as vomiting, some or severe dehydration and the need for intravenous fluid rehydration not only demonstrated stronger associations (larger ORs and lower $p$ values) with untreated/unboiled water in the second (20092103) time interval when compared to the first time interval (2004-2008), but also became significant factors in the logistic regression models constructed using them when comparing the two time periods. This increased severity of disease may simply be explained by greater burden of inoculation or more possibly increased virulence of these organisms. Son et al studied 11 strains (10 clinical isolates from the icddr, $b$ and a representative strain from the 2010 Haiti cholera outbreak) all of which produced 2-10 folds increased CT (cholera toxin) compared to that of wild type El Tor strains under in vitro inducing 
conditions, with various TcpA and ToxT expression profiles. ${ }^{11}$ Particularly, El Tor variant MQ1795, which produced the highest level of CT and very high levels of TcpA and ToxT, demonstrating hypervirulence compared to the virulence of El Tor wild-type strains in the infant mouse cholera model. Intriguingly, Safaet al point out that there is sufficient evidence to indicate that the classical cholera toxin gene has reappeared with El Tor as its carrier. ${ }^{12,13}$ Given the fact that cholera caused by the classical biotype is more severe, one speculates whether these 'hybrid' strains which have spread to several countries (in Asia, Africa, US Gulf coast) have conferred altered pathogenicity.

Interesting patterns emerged when scrutinizing data pertaining to concomitant infections with other pathogens. It was examined in the study, concomitant infections with rotavirus, shigella, and ETEC. There was a consistently strong association between concomitant infections with ETEC (along with VCO1) and water treatment. The percentage of cholera patients that did not boil their water and ended up co-infected with ETEC more than doubled when comparing the two time points (2004-2008:3\%; 2009-2013:7\%). Moreover, logistical regression analysis showed a decreased protective effect of concomitant infection with ETEC from 2004-2008 (OR 0.553 CI: $0.362-0.845$ ) to $2009-2013$ (OR $0.763 \mathrm{CI}$ : 0.676-0.862).

Concomitant infection of ETEC with vibrio cholerae $\mathrm{O} 1$ (70\% of the isolates being VCO1 Ogawa serotype, El Tor biotype) was reported by Chakraborty et al during an outbreak in Ahmedabad, India in January 2000. However, concurrent incidence of two different enteric pathogens, V. cholerae and ETEC, in a single patient was not encountered. ${ }^{9}$ Similar surveillances were made by Qadri et al in their paper when they concluded that contaminated water during floods (in this case the flooding in
Dhaka in July 2004) could be a potential cause of ETEC diarrhea independent of V. Cholerae O1. ${ }^{10}$ Hence, the nature of the relationship between V. Cholerae and ETEC requires further investigation.

\section{Conclusion}

In spite of the progress in socio-economics, high cholera prevalence remains. Since sustainable enhancements in water and sanitation infrastructures are still long-term solutions (because of densely populated areas with limited resources)-not to mention the unstable and unpredictable political climate that hinders implementation of plans that address socio-economic and environmental risk factors, supplementary avenues to intervene in the short run such as clinical management via vaccination needs to be explored. Furthermore, there is need for continued monitoring and surveillance to fully understand the changing clinico-pathologic facets of cholera and the emergence of hybrid and drug resistance strains if it is to effectively wage battle against this formidable foe.

Acknowledgement: This work was funded by the Australian Agency for International Development (AusAID), Government of the People's Republic of Bangladesh, Canadian International Development Agency (CIDA), Swedish International Development Cooperation Agency (Sida) and the Department for International Development, UK (DFID). Authors would like to thank all the study participants, field workers and the Dhaka Hospital staff for their contributions.

\section{References:}

1. GHO data;http://www.who.int/gho/epidemic _diseases/cholera/cases_text/en/.

2. Marshall, Andrew. In Bangladesh, A New Way to Fight Cholera. Time World. http://content.time.com/time/world/article/0, 8599,2048937,00.html. 
3. Faruque SM, Nityananda C, Kamruzzaman M, Ahmad QS, Faruque ASG, Salam MA et al. Reemergence of Epidemic Vibrio cholerae O139, Bangladesh. Emerg Infect Dis. 2003;9(9): 1116-22.

4. Stoll BJ, Glass RI, Huq MI, Khan MU, Holt JE, Banu H. Surveillance of patients attending a diarrhoeal disease hospital in Bangladesh. Br Med J (Clin Res Ed) 1982; 285:1185-88.

5. World Health Organization. 1987. Manual for laboratory investigations of acute enteric infections. Geneva: Programme for Control of Diarrhoeal Diseases, World Health Organization. 113 p. (CDD/83.3 Rev. 1, 1987).

6. Waldman RJ, Mintz ED, Papowitz HE. The Cure for Cholera-Improving Access to Safe Water and Sanitation. N Engl J Med. 2013; 368:592-594.

7. Harris AM, Chowdhury F, Begum YA, Khan AI, Faruque AS, Svennerholm AM, et al. Shifting prevalence of major diarrheal pathogens in patients seeking hospital care during floods in 1998, 2004, and 2007 in Dhaka, Bangladesh. Am J Trop Med Hyg. 2008; 79(5):708-14.

8. WHO and UN Water Report. GLAAS 2012 Report: UN-Water Global Analysis and Assessment of Sanitation and DrinkingWater. The Challenge of Extending and Sustaining Services.
9. Chakraborty S, Dekule JS, Garg P, Bhattacharya SK, Nandy RK, Nair GB et al. Concomitant infection of Enterotoxigenic Escherichia coli in an Outbreak of Cholera Caused by Vibrio cholerae O1 and O139 in Ahmedabad, India. J. Clin. Microbiol. 2001; 39 (9); 3241-46. .

10. Qadri F, Khan AI, Faruque ASG, Begum YA, Chowdhury F, Nair GB et al. Enterotoxigenic Escherichia coli and Vibrio cholerae Diarrhea, Bangladesh, 2004. Emerg Infect Dis. 2005; 11(7): 1104-1107.

11. Son MS, Megli CJ, Kovacikova G, Qadri F, Taylor RK. Characterization of Vibrio cholerae O1 El Tor Biotype Variant Clinical Isolates from Bangladesh and Haiti, Including a Molecular Genetic Analysis of Virulence Genes. J ClinMicrobiol. 2011; 49 (11): 3739-49.

12. Safa A, Bhuyian NA, Nusrin S, Ansaruzzaman M, Alam M, Hamabata T et al. Genetic characteristics of Matlab variants of Vibrio cholerae $\mathrm{O} 1$ that are hybrids between classical and El Tor biotypes. J Med Microbiol. 2006; 55 (Pt 11): 1563-69.

13. Safa A, Sultana J, Cam PD, Mwansa JC, Kong RYC. Vibrio cholerae O1 Hybrid El Tor Strains, Asia and Africa. Emerg Infect Dis. 2008; 14 (6): 987-88.

14. Woirld Health Organization. Cholera Vaccines: WHO position paper. No13, 2010, 85, 117-128. Geneva: WHO;2010. http://www.who.int/wer 